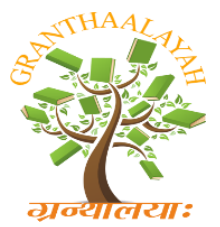

\author{
INTERNATIONAL JOURNAL OF RESEARCH - \\ GRANTHAALAYAH \\ A knowledge Repository
}

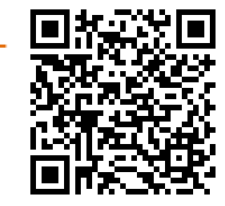

\title{
RECYCLING AND PYROLYSIS OF WASTE PLASTICS
}

\author{
Amrita Khatri \\ MJB Govt. P.G. Girls College, Moti Tabela, Indore
}

\begin{abstract}
Plastic has achieved such an extensive market due to fact that it is lightweight, cheap, flexible and reusable. But now it is regarded as a serious hazard. All recommendation for and against plastics finally land up on the reality that plastics are slow to degrade. By the end of the 20th century, plastics are found as persistent polluters of many environmental niches, from Mount Everest to the bottom of the sea. There are numerous ways by which plastic pollution can be controlled. Pyrolysis is referred to as polymer cracking and its main advantages are that it can deal with plastic waste .This paper provides an overview of the science and technology of pyrolysis of waste plastics. The major advantage of the pyrolysis technology is its ability to handle unsorted, unwashed plastic. The production of gasoline, kerosene and diesel from waste plastics is an emerging technological solution to the vast amount of plastics that cannot be economically recovered by conventional mechanical recycling. The disposal and decomposition of plastics has been an issue which has caused a number of research works to be carried out in this regard. Currently, the paper reviews the production of Petroleum-based fuel viz. gasoline, kerosene and diesel from recycling of waste plastics is an emerging technological solution to the vast amount of plastic wastes that cannot be economically recovered by conventional mechanical recycling operations. This involves the use of pyrolysis which permits recovery of valuable gasoline and diesel-range hydrocarbons from waste plastics that are otherwise land filled.
\end{abstract}

\section{Keywords:}

Plastic, nuisance, non-biodegradable, recycling, pyrolysis.

\section{INTRODUCTION}

Rapid industrialization and population explosion in India has led to the migration of people from villages to cities, which generate thousands tons of municipal solid waste daily, which is one of the important contributors for environmental degradation at national level. Improper management of municipal solid waste (MSW) causes hazards to inhabitants (Singh et al.2011.)

Plastics is extensively used by the people and is referred to as one of the greatest advancement of the millennium The prominence of plastic pollution is correlated with plastics being inexpensive and durable, which lends to high levels of plastics used by humans(Hester\& Harrison, 2011). But it is turning out to be a threat. Plastic pollution has the potential to poison animals, which can then adversely affect human food supplies (Daniel \& Chiras, 2004). In future, the earth may be completely covered with plastics and humans will be living over it. Since plastics are non- 
biodegradable, they cannot be easily returned to the natural carbon cycle; hence the life cycle of plastic materials ends at waste disposal facilities (Luo et al.,2007)

Pyrolysis can be used to convert plastic which is longer hydrocarbon into smaller units of hydrocarbon like naphtha, diesel etc. Thermal pyrolysis of plastic waste leads to the production of fuel oil, valuable resource recovery and reduction of waste problem it has been shown that the conversion at lower temperature in the presence of catalyst into liquid is a feasible process (Garib Alla et al. 2014)

An alternative strategy is Pyrolysis for chemical recycling, which has attracted much interest recently, with the aim of converting waste plastics into basic petrochemicals or fuel oil for a variety of downstream processes( Panda et al. 2010) .Pyrolysis is a tertiary or feedstock recycling technique capable of converting plastic waste into fuels, monomers, or other valuable materials by thermal and catalytic cracking processes .Pyrolysis process are two types based on temperature: low-temperature vacuum pyrolysis and high-temperature pyrolysis The disposal and decomposition of plastics has been an issue which has caused a number of research works to be carried out in this regard. Currently the disposal methods employed are land filling, mechanical recycling, biological recycling, thermal recycling, and chemical recycling. Because of this, since 1950 plastics production has gone up by almost $10 \%$ every year on a global basis (Panda et al., 2010). Asia accounts for $36.5 \%$ of the global consumption and has been world's largest plastics consumer for several years. The major segment involves in the packaging, which has accounted for over $35 \%$ of the global demand.

The work focused on thermal cracking of waste plastic to change them into usable resources, because in this method the emission of hazardous gases to the environment insignificant. This means one can change all the waste in to useful resources (Abatneh \& Sahu, 2013). It was observed that the percentage yield of gases were more in case of thermal degradation when compared with catalytic method (pyrolysis) and it was increased with the rose in reaction temperature( Nagori \& Dohare , 2014).The conversion of plastic waste into fuel is beneficial. The gas emissions and ash produced in the process also falls under the conditions against pollution (Ingle et al., 2014)

Akash Vashishtha posted that India will soon be able to convert its plastic wastes into high-grade petrol and diesel by researchers at the Dehradun-based Indian Institute of Petroleum (IIP) (Mail Online India, Aug.2015 ). The 2015 International Coastal Cleanup date is Saturday, September 19th, which is designed to dissociate the oceans's plastic pollution by the world's first system near Japan in 2016, with the aim of ultimately detained half of the plastic found in the Great Pacific Garbage Patch - a large concentration of marine debris located between Hawaii and California.) Boyan Slat, a Dutch entrepreneur, founder and CEO of The Ocean Cleanup 20-year old founder and CEO of The Ocean Cleanup Foundation, also announced that the world's first to passively clean up Ocean plastic pollution from the world's oceans is to be organized in 2016.

\section{REFERENCES}

1. Abatneh Y. \& Sahu O. (2013) The Conversion Of Different Waste Plastics Into Fuel Oil International Journal of Scientific \& Technology 2( 5): 29-31

2. Daniel D. Chiras (2004) : Creating a Sustainable Future. Jones \& Bartlett Learning. Environmental Science 7th edition, 517-518.

3. Garib Alla M M, Ahmed A I \& Abdalla B K (2014) Conversion of plastic waste to liquid fuel International Journal of Technical Research and Applications 2(3):29-31

4. Hester, R. E.; Harrison, R. M. (2011). Marine Pollution and Human Health. Royal Society of Chemistry. 84-85. 
5. Ingle $R$, Masal $R$ \& Gargade (2014) Obtaining Fuels from Plastic Waste International Journal on Recent and Innovation Trends in Computing and Communicatio $n 2(4): 218-220$

6. Luo, Suto T, Yasu $S$ \& Kato K (2007) Catalytic degradation of high density polyethylene and polypropylene into liquid fuel in a powderparticle fluidized bed. Polym Degrad Stabil, 70: 97-10

7. Nagori K. \& Dohare( 2014) Conversion of selected waste Plastic in to Synthetic Fuel (Synthetic Diesel) International Journal of Engineering Sciences \& Research Technology 3(9):471-475

8. Panda A. K., . Singh R. K, and Mishra D. K.,(2010.) Thermolysis of waste plastics to liquid fuel. A suitable method for plastic waste management and manufacture of value added products - a world prospective, Renewable and Sustainable Energy Reviews, 14(1): 233248 ,

9. Singh R. P, Tyagi VV,Allen T. Ibrahim M H \& Kothari R. (2011) An overview for exploring the possibilities of energy generation from municipal solid waste (MSW) in Indian scenario Renewable and Sustainable Energy Reviews 15( 9): 4797-4808. 